\title{
The effect of restricted grazing on the fatty acid composition of ovine milk fat during early lactation
}

\author{
BY E. PAYNE AND P. V. RATTRAY \\ Ruakura Agricultural Research Centre, Ministry of Agriculture and Fisheries, \\ Hamilton, New Zealand
}

(Received 24 September 1979 - Accepted 28 November 1979)

I. The fatty acid composition of milk fat of Coopworth sheep offered varying pasture allowances has been determined after $\mathrm{I}, 14$ and $35 \mathrm{~d}$ of lactation. Differences in fatty acids occurred, particularly between $I$ and $14 \mathrm{~d}$, with a major increase in $C_{18: 0}$ whilst $C_{16: 0}, C_{16: 0}$ and $C_{18: 8}$ showed decreases.

2. When pasture allowances were restricted there were decreases in the short-chain fatty acids from $\mathrm{C}_{6}$ to $C_{14}$ and an increase in $C_{18: 1}$ as has been observed previously for cattle. The $C_{18: 1}: C_{10}$ value is a convenient measure of these changes and can be determined more rapidly than determining all the lower fatty acids.

3. The increased demand for milk resulting from suckling twin lambs caused an increase in $C_{18: 1}$ and decreases in $\mathrm{C}_{10}$ and $\mathrm{C}_{12}$ due to an increased utilization of body reserves.

4. The level of linoleic acid was much greater than has been previously observed in sheep given hay and contributes to the rapid rise in linoleic acid levels in lambs born under grazing conditions.

There are comparatively few reports of the fatty acid composition of sheep milk, particularly from a grazing situation. Early analyses by Hilditch \& Jasperson (I944) were obtained by fractional distillation of bulk milk fat. Similarly Gerson et al. (1958) analysed for milk fatty acids from New Zealand sheep and found some differences from the results of Hilditch \& Jasperson (1944). In particular the oleic acid content was higher and the palmitic acid content was lower.

Noble et al. (1970) were the first to analyse sheep milk fat by gas-liquid chromatography and reported basically similar analyses to Hilditch \& Jasperson (I944). This was the first report on the levels of polyunsaturated fatty acids measured individually and they also measured fatty acid composition $\mathrm{I}, 3$ and $100 \mathrm{~d}$ after lambing.

In New Zealand it seemed likely that all grass rations could lead to higher levels of linoleic acid in milk which is of interest in relation to polyunsaturated fatty acid status of newborn lambs (Payne, 1978). In addition there is no information on the effect of restricted intakes on fatty acid composition as in cattle (Stobbs \& Brett, 1974, 1976).

This communication reports on the fatty acid composition of the milk fat of ewes suckling either single or twin lambs during early lactation and subjected to varying grazing restrictions.

\section{MATERIALS AND METHODS}

\section{Experimental design and management}

Pregnant Coopworth ewes grazed continuously were identified as single-bearing and twinbearing by X-ray at day 90 of gestation. For the last 6 weeks of gestation, 54 sheep (equal numbers of single- and twin-bearing ewes) were run at three different mean pasture allowances (low (L), medium (M) and high (H)) by allocation of different grazing areas with similar pasture cover of ryegrass and white clover (Table 1 ).

Sheep were moved when the twin-bearing group $\mathrm{L}$ had utilized approximately $700 \mathrm{~g}$ $\mathrm{DM} / \mathrm{kg}$ available. Intake (DM disappearance) was estimated by cutting quadrats of pasture before and after grazing to ground level using an enclosure technique. Following lambing 


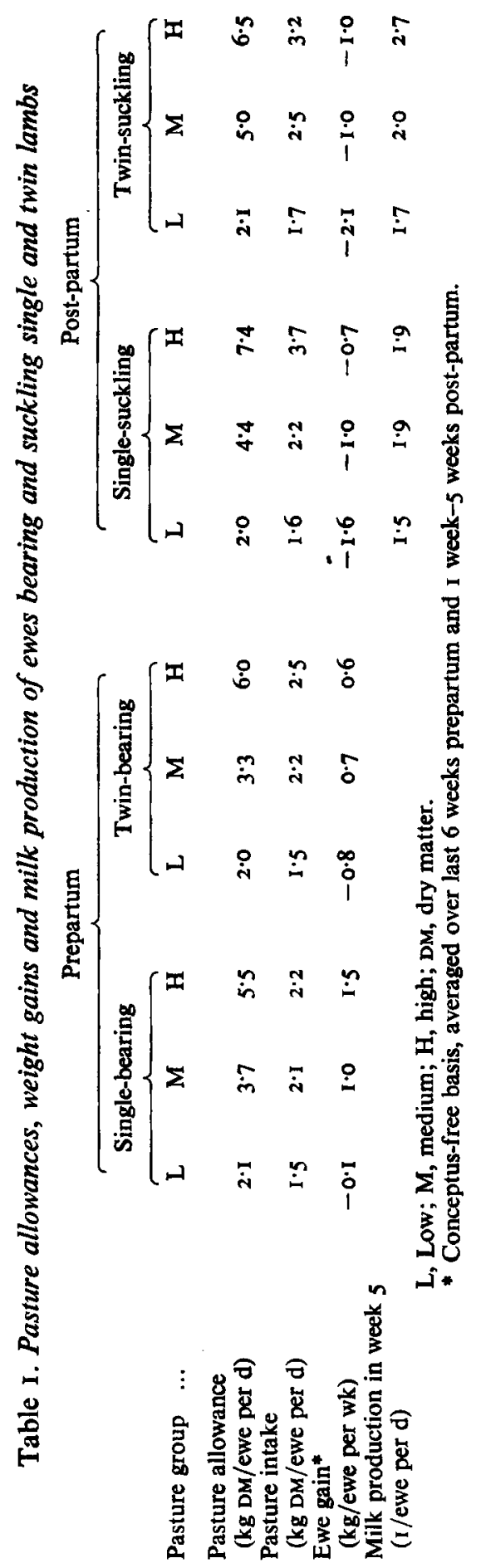


and first milking each group was re-randomized between the three levels of pasture allowance indicated in Table $\mathbf{I}$.

\section{Milk sampling}

Milk production was estimated once weekly from the day after birth using a technique similar to that of McCance (1959). Samples of milk were immediately extracted or frozen at $-20^{\circ}$ until analysed for fatty acid composition.

\section{Fatty acid analysis}

Milk ( $2 \mathrm{ml}$ ) was mixed with $2 \mathrm{ml}$ ethanol and then $5 \mathrm{ml}$ light petroleum (b.pt $40-60^{\circ}$ ) were added and the mixture shaken well. A I ml portion of the light petroleum layer was evaporated in a $8 \times 60 \mathrm{~mm}$ glass-stoppered tube and the residue dissolved in $0.2 \mathrm{ml}$ light petroleum. The butyl esters were formed by a modification of the method of Parodi (1970). This involved the addition of $0.01 \mathrm{ml} 3 \mathrm{M}$-potassium hydroxide in butanol followed after $5 \mathrm{~min}$ by I $\mathrm{ml}$ saturated sodium chloride solution. After shaking and centrifugation the butyl esters were separated on a Hewlett Packard FM402 gas chromatograph using a I.8 m column of $170 \mathrm{~g}$ diethyleneglycol succinate (DEGS)/kg 100-I 20 mesh Gas Chrom Q (Applied Science Laboratories) with temperature programming from 100 to $180^{\circ}$. Relative areas were determined using a Varian CDIor integrator. No correction for response was necessary. In the identification of some of the fatty acids use was made of a $1.8 \mathrm{~m}$ column of $170 \mathrm{~g}$ butanediol succinate (BDS)/kg Gas Chrom Q. Identification of fatty acids was primarily by comparison of the equivalent chain lengths (ECL) of butyl and methyl esters derived under isothermal conditions $\left(175^{\circ}\right)$ with published values for DEGS and BDS stationary phases. Unsaturated fatty acid esters were also detected by removal with bromine and by separation by argentation thin layer chromatography (Morris, I 962 ) on plates of $50 \mathrm{~g}$ silver nitrate $/ \mathrm{kg}$ silica gel G using a solvent of hexane:diethyl ether:acetic acid (80:20:I) together with relevant standards. After detection with Rhodamine $6 \mathrm{G}$ spray bands were scraped off and eluted in microcolumns with diethyl ether (freshly-opened May \& Baker A.R.). Following evaporation under dry nitrogen and redissolving in hexane the esters were separated by isothermal gas-liquid chromatography as before.

\section{RESULTS}

Table 2 shows the mean fatty acid composition of milk fat on I, 14 and $35 \mathrm{~d}$ of lactation. As statistical analysis showed that at $14 \mathrm{~d}$ there were still effects from the ration fed before lambing in those lambs that changed allowance, the results in Table 2 are confined to those ewes which did not change ration at lambing.

It can be seen that there were increases in fatty acids such as 10:0 and 18:0 during lactation, whereas $14: 0$ particularly and to a lesser extent $16: 0$ and $18: 3$ showed decreases. Fatty acids $A$ and $B$ have not been identified but were dienoic acids with equivalent chainlengths of $19: I$ and $19: 6$ on DEGS compared with $19: 3$ for linoleic acid. Presumably they were isomers of linoleic acid. In the $14 \mathrm{~d}$ samples the analysis did not resolve fatty acid B sufficiently from $18: 2$ to allow measurement.

When pasture allowance was restricted to $2 \mathrm{~kg} / \mathrm{ewe}$ per $\mathrm{d}$ during the first $35 \mathrm{~d}$ of lactation there was a significant lowering of most fatty acids less than $\mathrm{C}_{\mathbf{1 4}}$ and an increase in $\mathrm{C}_{\mathbf{1 8 : 1}}$ (Table 3). The only acid less than $C_{14}$ to be unchanged was $C_{4}$. The $C_{18: 1}: C_{10}$ value also showed a highly significant change. The allocation of the $M$ pasture allowance resulted in a similar fatty acid composition to the $\mathbf{H}$ allowance.

Similar changes were also observed at I $\mathrm{d}$ post-partum due to the restricted allowance before lambing. At this time $\mathrm{C}_{18: 1}: \mathrm{C}_{10}$ value in the well-fed ewes was 7.0 whilst for the restricted ewes the value was $10 \cdot 2$. 
Table 2. The variation in fatty acid composition $(\mathrm{g} / \mathrm{kg})$ of milk fat during early lactation (Mean values for no. of animals given in parentheses)

\begin{tabular}{|c|c|c|c|c|c|}
\hline \multirow[b]{2}{*}{ Fatty acid } & \multicolumn{3}{|c|}{ Period post-partum (d) } & \multirow{2}{*}{$\begin{array}{c}\text { sE } \\
\text { of mean } \\
\text { difference }\end{array}$} & \multirow{2}{*}{$\begin{array}{l}\text { Statisti } \\
\text { significa } \\
\text { of differe }\end{array}$} \\
\hline & $\begin{array}{l}I \\
(16)\end{array}$ & $\begin{array}{r}\text { I4 } \\
(\mathrm{I} 6)\end{array}$ & $\begin{array}{c}35 \\
\text { (16) }\end{array}$ & & \\
\hline $4: 0$ & 26 & 44 & 33 & 4 & 一 \\
\hline $6: 0$ & $2 I$ & 28 & 21 & 3 & 一 \\
\hline $8: 0$ & 18 & 22 & 20 & 2 & - \\
\hline $10: 0$ & 40 & 57 & 52 & 4 & ** \\
\hline $12: 0$ & 29 & 31 & 29 & 3 & - \\
\hline $14: 0$ & 86 & 58 & 57 & 7 & $* * *$ \\
\hline $15: 0 \mathrm{br}$ & 7 & 6 & 7 & I & 一 \\
\hline $15: 0$ & 9 & 10 & II & $\mathbf{I}$ & - \\
\hline 16:0 br & 3 & 4 & 4 & I & 一 \\
\hline $16: 0$ & 195 & 154 & 167 & 6 & $* *$ \\
\hline $16: 1+17: 0 \mathrm{br}$ & $3 \mathrm{I}$ & 26 & 28 & 2 & - \\
\hline $17: 0$ & 13 & I3 & 13 & $\mathbf{I}$ & $\rightarrow$ \\
\hline $17: 1+18: 0$ br & 7 & 8 & 8 & I & 一 \\
\hline $18: 0$ & 95 & 133 & 147 & 9 & $* *$ \\
\hline $18: 1$ & 293 & 315 & 322 & 13 & - \\
\hline $\mathbf{A}$ & 12 & 10 & 8 & 2 & - \\
\hline $18: 2$ & 28 & 24 & 23 & 3 & - \\
\hline $\mathbf{B}$ & 12 & - & 3 & 2 & - \\
\hline $18: 3$ & 45 & 35 & 29 & 2 & $* *$ \\
\hline
\end{tabular}

br, Iso or ante-iso branched chain acid. $* * P<0.01, * * * P<0.001$.

Table 3. The effect of restricted pasture allowance on fatty acid composition $(\mathrm{g} / \mathrm{kg})$ of milk fat 35 d post-partum

(Mean values for no. of animals given in parentheses)

Pasture allowance

\begin{tabular}{|c|c|c|c|c|}
\hline \multirow[b]{2}{*}{$\begin{array}{l}\text { Fatty } \\
\text { acid }\end{array}$} & & \multirow{2}{*}{$\begin{array}{c}\text { SE } \\
\text { of mean } \\
\text { difference }\end{array}$} & \multirow{2}{*}{$\begin{array}{l}\text { Statistical } \\
\text { significance } \\
\text { of difference }\end{array}$} \\
\hline & $\begin{array}{c}\text { Low } \\
(15)\end{array}$ & $\begin{array}{c}\text { High } \\
\text { (I } 7)\end{array}$ & & \\
\hline $4: 0$ & 36 & 37 & 2 & - \\
\hline $6: 0$ & 18 & 22 & I & $* *$ \\
\hline $8: 0$ & 16 & 22 & $\mathbf{I}$ & $* * *$ \\
\hline $10: 0$ & 36 & 56 & 3 & $* * *$ \\
\hline $12: 0$ & 20 & 31 & 2 & $* * *$ \\
\hline $14: 0$ & 53 & 60 & 4 & $\bullet$ \\
\hline $16: 0$ & 178 & 164 & 5 & ** \\
\hline 16:1 & 28 & 27 & I & - \\
\hline $18: 0$ & I 54 & 150 & 4 & - \\
\hline 18:1 & 357 & 309 & 9 & $* * *$ \\
\hline $18: 2$ & 21 & 17 & 2 & - \\
\hline $18: 3$ & 26 & 27 & I & - \\
\hline $4-14$ & 179 & 229 & 10 & $* * *$ \\
\hline $18: 1: 10$ & 10.9 & $5 \cdot 9$ & 0.9 & $* * *$ \\
\hline
\end{tabular}

Since suckling twin lambs usually leads to greater demands on the ewe the effect of suckling twins on milk fatty acid composition was examined (Table 4). It can be seen that suckling twins resulted in increased $\mathrm{C}_{18: 1}$ and decreased short-chain acids with an increased $\mathrm{C}_{18: 1}: \mathrm{C}_{10}$. 
Table 4. The effect of suckling single or twin lambs on the fatty acid composition $(\mathrm{g} / \mathrm{kg})$ of ovine milk 35 d after lambing

(Mean values for no. of animals given in parentheses)

\begin{tabular}{|c|c|c|c|c|}
\hline Fatty acid & $\begin{array}{c}\text { Ewes } \\
\text { single- } \\
\text { suckled } \\
(24)\end{array}$ & $\begin{array}{c}\text { Ewes } \\
\text { twin- } \\
\text { suckled } \\
(25)\end{array}$ & $\begin{array}{c}\text { SE } \\
\text { of mean } \\
\text { difference }\end{array}$ & $\begin{array}{l}\text { Statistical } \\
\text { significance } \\
\text { of difference }\end{array}$ \\
\hline $4: 0$ & 38 & 37 & I & 一 \\
\hline $6: 0$ & 23 & 21 & I & - \\
\hline $8: 0$ & 2 I & 19 & I & - \\
\hline $10: 0$ & 52 & 46 & 3 & * \\
\hline $12: 0$ & 30 & 26 & $2 \cdot 6$ & $*$ \\
\hline $14: 0$ & 58 & 60 & 3 & - \\
\hline $16: 0$ & 166 & 175 & 4 & $* *$ \\
\hline $18: 0$ & 149 & 147 & 3 & - \\
\hline $18: 1$ & 309 & 329 & 7 & $* *$ \\
\hline $18: 2$ & 22 & 21 & I & - \\
\hline $18: 3$ & 27 & 27 & 1 & - \\
\hline $18: 1: 10$ & 6.6 & 8.2 & 0.7 & * \\
\hline
\end{tabular}

The fatty acid composition of milk fat from sheep grazing lush pastures differed in several respects from the results of Noble et al. (1970) for sheep given hay and concentrates. The levels of short-chain acids were observed to be higher whilst those of oleic and palmitic acids were very much lower. This was in line with the early results of Gerson et al. (1958).

Perhaps the greatest differences were in the polyunsaturated acids. Linoleic acid (I8:2) was very much higher in our study and we also recorded the presence of other $18: 2$ isomers. The significant peak corresponding to $C_{18: 3}, C_{20: 1}$ and conjugated $C_{18: 2}$ has not previously been recorded for ovine milk fat in the literature, possibly because little significance has been attached to it. Later investigations using a BDS column which separates these acids have shown that the peak was predominantly $\mathrm{C}_{18: 3}$.

Undoubtedly the greater quantities of the polyunsaturated acids could well be due to grazing on lush pasture. The lipid of ryegrass at Ruakura has a polyunsaturated fatty acid composition (E. Payne, unpublished results) similar to the high levels reported for ryegrass by Hudson \& Karis (1974) compared to the much lower levels reported for hay by Moore et al. (1968).

The changes in fatty acid composition during lactation differed from those of Noble et al. (1970) who sampled at the beginning and end of lactation and Gerson et al. (1958) who did not sample at the beginning of lactation. The reasons for the changes are difficult to determine as some short-chain acids decreased whilst others increased. Stearic acid and palmitic acid also moved reciprocally.

The change in composition with restricted pasture allowance was similar to previous observations in lactating cattle (Stobbs \& Brett, 1974, 1976; Payne et al. 1979) where it has been proposed that the change in fatty acid composition could be used to assess energy status of the herd. Indeed the $C_{18: 1}: C_{10}$ value was rather similar in ovine milk to that in bovine milk. Thus values of 5-7 reflected a fully-fed flock whereas values of 10 and higher reflected underfeeding and mobilization of body fat. The fact that the $M$ allowance did not result in a value different from that with the $H$ allowance suggests that $C_{18: 1}: C_{10}$ may not be very sensitive, particularly when with single suckling there was a weight loss between the $\mathrm{H}$ and $\mathrm{M}$ allowance and with twin suckling there was a drop in milk production. If we 
calculate the $\mathrm{C}_{18: 1}: \mathrm{C}_{10}$ value for the results of Noble et al. (1970) it can be seen that the values of the first $3 \mathrm{~d}$ of lactation were very high (23-45). This possibly indicates the sheep were mobilizing fat at this stage.

The effect of the number of lambs suckling on fatty acid composition was in line with the live-weight loss and an increased utilization of body reserves with a consequent rise in $\mathrm{C}_{18: 1}$ acid by the ewes suckling twins as well as increased intake (see Table I) to allow increased milk production.

These results suggest that the fatty acid composition of ovine milk fat varies with food intake, time of lactation and numbers of lambs suckled. Though insensitive to small changes of intake in well-fed sheep, $\mathrm{C}_{18: 1}: \mathrm{C}_{10}$ could be useful as an indication of major energy deficiency, particularly early in lactation.

The authors would like to thank Carol Kevey for the collection of milk samples, Jewell Jackson and C. Pyle for skilled technical assistance and D. Duganzich for statistical analyses.

\section{REFERENCES}

Gerson, T., Shorland, F. B. \& Barnicoat, C. R. (1958). Biochem. J. 68, 644.

Hilditch, T. P. \& Jasperson, H. (1944). Biochem. J. 38, 443.

Hudson, B. J. F. \& Karis, I. G. (1974). J. Sci. Fd Agric. 25, 1491.

McCance, I. (1959). Aust. J. agric. Res. ro, 839.

Moore, J. H., Noble, R. C. \& Steele, W. (1968). Br. J. Nutr. 22, 68 I.

Morris, L. J. (1962). Chemy Ind., p. 1238.

Noble, R. C., Steele, W. \& Moore, J. H. (1970). J. Dairy Res. 37, 297.

Parodi, P. (1970). Aust. J. Dairy Tech. 25, 200.

Payne, E. (1978). Br. J. Nutr. 39, 53.

Payne, E., Trigg, T. E., Rattray, P. V., Nicoll, G. B. \& Smeaton, D. C. (1979). Proc. N.Z. Soc. Anim. Prod. 39, 233.

Stobbs, T. H. \& Brett, D. J. (1974). Aust. J. agric. Res. $25,657$.

Stobbs, T. H. \& Brett, D. J. (1976). Aust. J. agric. Res. $27,175$. 